\title{
AVALIAÇÃO DE INJÚRIAS DE POLYPHAGOTARSONEMUS LATUS BANKS (ACARI: TARSONEMIDAE) EM GENÓTIPOS DE ALGODOEIRO
}

\author{
C. Goulart ${ }^{1 *}$, E. Cia ${ }^{1}$, M.G. Fuzatto ${ }^{1}$, R.R. Lüders ${ }^{1}$, A.L. Lourenção ${ }^{1,2}$ \\ ${ }^{1}$ Instituto Agronômico, Centro de Pesquisa e Desenvolvimento de Grãos e Fibras, CP 28, CEP 13001-970, \\ Campinas, SP, Brasil. E-mail: goulart_carlos07@yahoo.com.br
}

\section{RESUMO}

\begin{abstract}
As injúrias causadas pelo ácaro-branco em cultivares e linhagens avançadas de algodoeiro disponíveis no Brasil foram avaliadas em três experimentos de campo conduzidos em Campinas, SP (2001/2002 e 2005/2006) e em Guairá, SP (2003/2004). As áreas experimentais foram instaladas segundo um delineamento de blocos ao acaso, com seis repetições, sendo as parcelas constituídas por uma linha de $5 \mathrm{~m}$ de comprimento. No total, 36 genótipos diferentes foram utilizados. Foram estabelecidos 16 tratamentos em 2001/2002 e 2003/2004 e 18 em 2005/2006. A avaliação foi feita após intensa ocorrência da praga, sem realização de controle químico, sendo atribuídas, em nível de parcelas, notas de 1 a 5, crescentes com o tipo e a intensidade dos sintomas. Verificou-se, nos três experimentos, ampla e gradual diversidade entre os genótipos, com as notas médias variando de 1,77 (IAC 23) até 4,20 (Sure Grow 821) no experimento de 2001/2002, de 1,45 (COODETEC 401) a 4,63 (MG 0110) no experimento de 2003/2004 e de 1,86 (FMT 702) a 4,74 (Stoneville 474) no experimento de 2005/2006. A análise conjunta de quatro genótipos comuns aos três experimentos corroborou as evidências de ampla e gradual diferença entre os genótipos, indicando IAC 24 e Fibermax 966 como menos danificadas e Deltaopal e Makina como as mais afetadas.
\end{abstract}

PALAVRAS-CHAVE: Gossypium hirsutum, ácaro-branco, resistência de plantas.

\section{ABSTRACT}

EVALUATIONOFCOTTONGENOTYPESTOINJURYCAUSEDBY POLYPHAGOTARSONEMUS LATUS BANKS (ACARI: TARSONEMIDAE). Injuries caused by broad mite to the main cotton cultivar and advanced lineages available presently in Brazil were evaluated in three field experiments. In a randomized block design with 6 replications, the plots consisting of a 5-m-long row, the trials were carried out in the 2001/2002 and 2005/2006 season at Campinas, SP, and in 2003/ 2004 at Guaíra, SP, Brazil. A total of 36 different genotypes were used. Sixteen treatments were carried out in 2001/2002 and 2003/2004, and 18 in 2005/2006. Evaluation was performed by attribution of scores from 1 to 5 to the entire plots, according to the level of injury caused to plant leaves. In all the experiments, wide and gradual differences among genotypes were observed, with mean scores varying from 1.77 (IAC 23) to 4.20 (Sure Grow); 1.45 (Coodetec 401) to 4.63 (MG 0110) and 1.86 (FMT 702) to 4.74 (Stoneville 474), respectively in the 2001/2002, 2003/2004 and 2005/2006 trials. Joint analysis involving four cultivars common to the three experiments corroborates the results, indicating IAC 24 and Fibermax 966 as the least affected, and Deltaopal and Makina as the most injured.

KEY WORDS: Gossypium hirsutum, broad mite, host plant resistance.

\section{INTRODUÇÃO}

Cosmopolita e polífago, o ácaro-branco Polyphagotarsonemus latus (Banks) (Acari: Tarsonemidae) tem ocorrência em regiões tropicais e subtropicais, sendo relatado infestando plantas de diversas famílias (GERSON, 1992). É praga primária em algodoeiro, atacando as folhas mais novas da planta, provocando enrolamento dos bordos para baixo e formação de um aspecto vítreo na face ventral da folha; como último estádio do ataque, ocorrem rasgaduras (GAllo et al., 2002). Segundo Oliveira; CalCagnolo (1974), o ataque do ácaro-branco pode ocasionar perdas de até $11 \%$ na produção de algodão em caroço, além de depreciar a qualidade das fibras. Vieira; Chiavegato (1998), estudando a biologia do

\footnotetext{
${ }^{2}$ Instituto Agronômico, Centro de Pesquisa e Desenvolvimento de Fitossanidade, Campinas, SP, Brasil.
} 
ácaro em algodoeiro, a $28,5^{\circ} \mathrm{C}$ e $71 \%$ de umidade relativa, observaram: duração do ciclo de ovo a adulto de 4,1 dias para fêmeas e machos; longevidade de fêmeas de 10 dias e de machos 8,8 dias; período de oviposição de 6,8 dias; e oviposição diária de 4,5 ovos por fêmea. O tempo médio de uma geração $(\mathrm{T})$ foi de 9,54 dias e a taxa líquida de reprodução (Ro) de 21,73.

O uso de defensivos agrícolas tem sido a única opção de controle da praga. A aplicação de um mesmo produto por repetidas vezes e a elevação de dosagem pode acelerar o desenvolvimento de resistência, além da contaminação ambiental e a destruição de inimigos naturais (SANTOS, 1999).

Nos anos mais recentes, a incidência do ácarobranco com intensidade anormalmente alta em algodoeiros levou a que fosse sugerida a hipótese de que cultivares mais sensíveis ou propensas ao ataque dessa praga seriam a causa desse fato (FuzATTo et al., 1990; FuzATto et al.,1997). Os autores observaram alta variação de sintomas entre diferentes genótipos de algodoeiro ao ataque de $P$. latus, demonstrando a existência de diversidade genética nessa cultura, para resistência ao ácaro-branco.

Oobjetivo deste trabalho foi avaliar o desempenho de cultivares e linhagens de algodoeiro em relação às injúrias causadas pelo ácaro-branco, em três anos agrícolas.

\section{MATERIAL E MÉTODOS}

As avaliações foram realizadas em três experimentos de campo, em 2001/2002 em Campinas, SP, em 2003/2004 em Guaíra, SP, e em 2005/2006 em Campinas. Foram avaliados 16 genótipos em 2001/ 2002 e 2003/2004, e 18 genótipos em 2005/2006 (Tabelas 1, 2 e 3). Os três experimentos foram delineados em blocos ao acaso, com seis repetições, sendo as parcelas constituídas por uma linha de $5 \mathrm{~m}$ de comprimento. Foram realizados os plantios em 1/12/2001, 16/11/ 2003 e 22/11/2005 com, após desbaste final, estande de 30 plantas em 2001/2002, 35 plantas em 2003/2004 e 30 plantas em 2005/2006. Os experimentos foram adubados de acordo com as recomendações para a cultura (RAij etal.,1997). A avaliação do sintoma de ataque do ácaro-branco foi realizada após ocorrência da praga, sem realização do controle químico. A avaliação foi feita aos 90, 94 e 113 dias de emergência das plantas nos ensaios em 2001/2002, 2003/ 2004 e 2005/2006, respectivamente.

Foram atribuídas, em nível de parcelas, notas de 1 a 5, crescentes com a intensidade dos sintomas, de acordo com a escala proposta porFuzATTO et al.(1990): nota 1 - plantas sem sintomas visíveis nas folhas; nota 2 - poucas plantas com folhas apresentando coloração brilhante na face inferior e margens leve- mente dobradas para cima; nota 3 - a maioria das plantas com folhas exibindo os sintomas próprios da nota 2, algumas com folhas apresentando os bordos virados para baixo; nota 4 - a maioria das plantas apresentando folhas coriáceas, com bordos virados para baixo, algumas com rasgadura; nota 5 - a maioria das plantas com folhas encarquilhadas e apresentando rasgaduras.

Tabela 1 - Notas médias de injúrias provocadas por Polyphagotarsonemus latus em 16 genótipos de algodoeiro, no ano agrícola 2001/2002, Campinas, SP.

\begin{tabular}{lc}
\hline Genótipo & Média ajustada ${ }^{1}$ \\
\hline IAC 23 & $1,77 \mathrm{a}^{2}$ \\
Fibermax 986 & $2,02 \mathrm{ab}$ \\
IAC 24 & $2,22 \mathrm{abc}$ \\
PR 99-64 & $2,34 \mathrm{abc}$ \\
CNPA ITA 90 & $2,43 \mathrm{abc}$ \\
Fabrika & $2,46 \mathrm{abc}$ \\
Fibermax 966 & $2,79 \mathrm{bcd}$ \\
BRS Aroeira & $2,86 \mathrm{bcde}$ \\
FMT 97-1067 & $2,86 \mathrm{bcde}$ \\
COODETEC 405 & $2,96 \mathrm{bcdef}$ \\
IAC 23-924 & $3,03 \mathrm{bcdefg}$ \\
Deltaopal & $3,24 \quad \mathrm{cdefg}$ \\
DPL 4049 & $3,92 \quad$ defg \\
EPAMIG Precoce 1 & $4,00 \quad$ efg \\
Makina & 4,12 \\
Sure Grow 821 & 4,20 \\
\hline Teste F para genótipos & fg \\
Coeficiente de variação & $12,5^{* *}$ \\
Correlação intra-classe & 9,0
\end{tabular}

${ }^{1}$ Ajuste baseado em análise de covariância.

${ }^{2}$ Médias seguidas da mesma letra, na coluna, não diferem entre si pelo teste de Tukey $(\mathrm{P}<0,05)$.

Variações na intensidade dos componentes da nota levaram a que fossem atribuídos valores fracionários, intermediários ou próximos de uma ou outra nota da escala estabelecida. Para a análise de variância, as notas foram transformadas em $\sqrt{x}$, comparando-se as médias pelo teste de Tukey $(\mathrm{P} \leq 0,05)$.

Para verificar possível influência das parcelas adjacentes sobre a nota de cada parcela experimental, realizou-se análise de covariância, adotando-se como variável independente a média das notas dadas às duas parcelas adjacentes, o que implicou atribuir notas também às marginais externas do ensaio. Foi realizada análise conjunta das notas do ataque do ácaro-branco utilizando os quatro tratamentos repetidos (Deltaopal, IAC 24, Fibermax 966 e Makina) nos três anos de estudo. 
Tabela 2 - Notas médias de injúrias provocadas por Polyphagotarsonemus latus em 16 genótipos de algodoeiro, no ano agrícola 2003/2004, Guaíra, SP.

\begin{tabular}{lc}
\hline Genótipo & Média ajustada $^{1}$ \\
\hline COODETEC 401 & $1,45 \mathrm{a}^{2}$ \\
IAC RR 01/3 & $1,50 \mathrm{a}$ \\
IPR 140 & $1,63 \mathrm{a}$ \\
Fibermax 977 & $1,72 \mathrm{a}$ \\
BRS Jatobá & $1,88 \mathrm{ab}$ \\
Fibermax 966 & $1,92 \mathrm{ab}$ \\
IAC 24 & $1,92 \mathrm{ab}$ \\
IPR Jataí & $2,20 \mathrm{ab}$ \\
Fabrika & $2,22 \mathrm{ab}$ \\
BRS Ipê & $2,53 \mathrm{bc}$ \\
Deltapenta & $3,03 \mathrm{~cd}$ \\
Deltaopal & $3,40 \mathrm{de}$ \\
COODETEC 406 & $3,52 \quad \mathrm{de}$ \\
Stoneville 474 & $3,83 \mathrm{e}$ \\
Makina & $4,08 \mathrm{ef}$ \\
MG 0110 & 4,63 \\
\hline Teste F para genótipos & $16,3^{* *}$ \\
Coeficiente de variação & 11,9 \\
Correlação intra-classe & 0,72 \\
\hline
\end{tabular}

${ }^{1}$ Ajuste baseado em análise de covariância.

${ }^{2}$ Médias seguidas da mesma letra, na coluna, não diferem entre si pelo teste de Tukey $(\mathrm{P}<0,05)$.

Tabela 3 - Notas médias de injúrias provocadas por Polyphagotarsonemus latus em 18 genótipos de algodoeiro, no ano agrícola 2005/2006, Campinas, SP.

\begin{tabular}{|c|c|}
\hline Genótipo & Média ajustada $^{1}$ \\
\hline FMT 702 & $1,86 a^{2}$ \\
\hline IAC 25-RMD & $1,94 \mathrm{a}$ \\
\hline IAC 24 & $2,58 \mathrm{ab}$ \\
\hline CNPA CO 01-54472 & $2,64 \mathrm{ab}$ \\
\hline CNPA CO 00-337 & $2,80 \mathrm{abc}$ \\
\hline FMT 701 & $2,94 \mathrm{abcd}$ \\
\hline Fibermax 966 & $2,96 \mathrm{abcd}$ \\
\hline IPR 140 & $3,02 \mathrm{abcd}$ \\
\hline Deltaopal & 3,28 bcde \\
\hline IPR Jataí & 3,28 bcde \\
\hline COODETEC 409 & 3,58 bcdef \\
\hline Fibermax 977 & 3,92 cdef \\
\hline Deltapenta & 3,92 cdef \\
\hline Makina & 4,14 cdef \\
\hline COODETEC 410 & 4,16 def \\
\hline Epamig & 4,54 \\
\hline Destak & 4,72 \\
\hline Stoneville 474 & 4,74 \\
\hline Teste F para genótipos & $15,5^{* *}$ \\
\hline Coeficiente de variação & 16,4 \\
\hline Correlação intra-classe & 0,74 \\
\hline
\end{tabular}

${ }^{1}$ Ajuste baseado em análise de covariância.

${ }^{2}$ Médias seguidas da mesma letra, na coluna, não diferem entre si pelo teste de Tukey $(\mathrm{P}<0,05)$.
Tabela 4 - Análise conjunta de três anos (2001/2002, 2003/ 2004, 2005/2006) das notas médias de injúria provocada por Polyphagotarsonemus latus em quatro genótipos de algodoeiro, em dois ambientes do Estado de São Paulo.

\begin{tabular}{lcccc}
\hline Genótipo & $\begin{array}{r}2001 / \\
2002 \\
\text { Campinas }\end{array}$ & $\begin{array}{c}2003 / \\
\text { Guaíra }\end{array}$ & $\begin{array}{c}2005 / \\
2006\end{array}$ & Média \\
& Campinas & ajustada $^{(1)}$ \\
\hline IAC 24 & 2,22 & 1,92 & 2,58 & $2,24 \mathrm{a}^{2}$ \\
Fibermax 966 & 2,79 & 1,92 & 2,96 & $2,56 \mathrm{ab}$ \\
Deltaopal & 3,24 & 3,40 & 3,28 & $3,31 \mathrm{bc}$ \\
Makina & 4,12 & 4,08 & 4,14 & $4,11 \mathrm{c}$ \\
\hline Teste F para genótipos & & & $23,16^{* *}$ \\
Coeficiente de variação & & & 12,57 \\
\hline
\end{tabular}

${ }^{1}$ Ajuste baseado em análise de covariância.

${ }^{2}$ Médias seguidas da mesma letra não diferem entre si pelo teste de Tukey $(\mathrm{P}>0,05)$.

\section{RESULTADOS E DISCUSSÃO}

Experimento de 2001/2002. As diferenças foram altamente significativas, as notas médias variaram de 1,77 para a cultivar menos atacada (IAC 23), até 4,20 para a mais atacada (Sure Grow 821)(Tabela 1).

Efetuada análise de covariância, verificou-se influência pequena, porém significativa das linhas adjacentes sobre cada parcela experimental. Ajustadas as variâncias de tratamento e residual, houve aumento do Teste F, diminuição do coeficiente de variação $(\mathrm{CV})$ e aumento do coeficiente de correlação intra-classe. Embora o procedimento não tenha afetado substancialmente os dados originais, há indicação da necessidade de se observar o efeito das parcelas adjacentes no planejamento e eventuais ajustes dos dados em futuros experimentos como este.

Experimento de 2003/2004. Como no experimento anterior, constatou-se que houve ampla diferença entre os genótipos (Tabela 2), com as notas médias variando de 1,45 (COODETEC 401) a 4,63 (MG 0110). O coeficiente de variação e a correlação intra-classe revelaram, aqui também, em experimento de boa precisão e consistência. É de se notar a repetibilidade de resultados nascultivares Fabrika, Deltaopal Makina, que apresentaram médias semelhantes às do ano anterior. Verifica-se, porém, pequena variação nas médias dos dois anos para a IAC 24, de 2,27 para 1,92. Esta discrepância indica a conveniência de repetir a avaliação do mesmo genótipo em anos ou ambientes diversos, para concluir com mais segurança sobre o seu grau de resistência.

Experimento de 2005/2006. Neste experimento também verificou-se notável diferença entre os genótipos, com as notas médias variando de 1,86 (FMT 702) a 4,74 (Stoneville 474). A despeito de um coeficiente de variação relativamente alto, as diferen- 
ças foram altamente significativas. O coeficiente de correlação intra-classe $(r=0,77)$ indicou boa consistência dos dados. A exemplo do que ocorreu no ensaio de 2001/2002, neste ano também verificou-se efeito significativo das linhas adjacentes sobre cada parcela experimental. Mesmo não tendo resultado em mudanças substanciais, o ajuste de médias, mediante analise de covariância, mostrou-se, portanto, conveniente.

A julgar pelos resultados obtidos com os nove genótipos que foram comuns aos dois experimentos (IAC 24, Fibermax 977, IPR 140, IPR Jataí, Fibermax 966, Deltapenta, Stoneville 474, Deltaopal e Makina), no ensaio de 2003/2004 a infestação da praga teria sido menor (média 2,64) do que no ano de 2005/2006 (média 3,54). Embora isso não tenha afetado o desempenho relativo dos genótipos - a correlação entre as notas dos dois anos foi de $r=0,70 *$ - em condições de menor infestação alguns genótipos, principalmente os seis primeiros dos citados, teriam sido superestimados quanto à resistência. Segundo LARA (1991), esteé um fato comum sob baixa infestação de pragas, e pode levar a conclusões equivocadas.

$\mathrm{Na}$ Tabela 4 encontram-se os dados de análise conjunta realizada nos três experimentos, com quatro genótipos comuns a eles. A despeito da interação genótipo $x$ ambiente significativa - devida ao comportamento atípico de IAC 24 e da Fibermax 966, no ano 2003/2004 - os resultados corroboram as evidências presentes nos experimentos individuais, isto é, ampla e gradual diferença entre os genótipos com respeito às injúrias provocadas pela praga.

Embora sendo nítida a existência de diferenças entregenótipos, nãose determinou, porém, os mecanismos de resistência ou mesmo as causas. Não foram localizados na literatura trabalhos enfocando a avaliação de algodoeiro para resistência ao ácaro-branco. Para o ácaro-rajado (Tetranychus urticae), SCHUSTER etal . (1972) detectaram antibiose em algodoeiro(Gossypium barbadense), na variedade Pima S-2, reduzindo a fecundidade e alongando o tempo de vida médio da praga. LeGE etal. (1995), estudando as concentrações de ácidos fenólicos e taninos condensados em seis genótipos de algodão, observaram que os genótipos com altos teores de uma dessas substâncias também apresentam altos teores da outra, sugerindo a hipótese de que a resistência observada nos genótipos pode ser atribuída a presença de altos teores dessas substâncias. Assim, em futuras avaliações de resistência do algodoeiro ao ácaro-branco deve-se tentar determinar os mecanismos e as causas de resistência, avaliandose fatores relacionados ao ácaro e substâncias do metabolismo secundário da planta. Tais informações são essenciais para um programa de melhoramento que visa incorporar resistência varietal a insetos e ácaros e a inserção de materiais com resistência a pragas em programas de manejo integrado.

\section{CONCLUSÕES}

- Houve ampla diversidade entre os genótipos de algodoeiro estudados com relação às injúrias causadas pelo ácaro-branco.

- Entre os genótipos comuns aos três anos de estudo, IAC 24 e Fibermax 966 foram menos danificados e Deltaopal e Makina os mais afetados.

- É relevante considerar, no planejamento de experimentos que avaliem as injúrias doácaro-branco no algodoeiro, em condições de campo, o efeito das bordaduras para eventuais ajustes dos dados originais.

\section{REFERENNCIAS}

FUZATTO, M.G.; CIA, E.; CHIAVEGATO, E.J.; LANDEL, M.G.A. Ataque diferencial de ácaro branco em linhagens de algodoeiro: uma reflexão sobre a "não preferência" como mecanismo de resistência a pragas. In: REUNIÃO NACIONAL DO ALGODÃO, 6., 1990, Campina Grande. Resumos. Campina Grande: EMBRAPA-CNPA, 1990. p.51.

FUZATTO, M.G.; ROSSETTO, C.J.; CIA, E.; CARVALHO, L.H.; CHIAVEGATO, E.J. Sensibilidade de genótipos de algodoeiro ao ataque de ácaro branco. In CONGRESSO BRASILEIRO DO ALGODÃO, 1., 1997, Fortaleza, CE. Anais. Campina Grande: EMBRAPACNPA, 1997. p.249-251.

GALLO, D.; NAKANO, O.; SILVEIRA NETO, S.; CARVALHO, R.P.L.; BAPTISTA, G.C.; BERTI FILHO, E.; PARRA, J.R.P.; ZUCCHI, R.A.; ALVES, S.B.; VENDRAMIM, J.D.; MARCHINI, L.C.; LOPES, J.R.S.; OMOTO, C. Entomologia agrícola. Piracicaba: FEALQ, 2002. $920 \mathrm{p}$

GERSON, U. Biology and control of the broad mite, Polyphagotarsonemus latus (Banks) (Acari:

Tarsonemidae). Experimental and Applied Acarology. v.13, p.163-178, 1992.

LARA, F.M. Princípios de resistência de plantas a insetos. 2.ed. São Paulo: Ícone, 1991. 336p.

LEGE, K.E.; COTHREN, J.T.; SMITH, C.W. Phenolic acid and condensed tannin concentrations of six cotton genotypes. Environmental and Experimental Botany, v.35, n.2, p. 241-249, 1995.

OLIVEIRA, C.A.L.; CALCAGNOLO, G. Ação do "ácaro branco" Polyphagotarsonemus latus (Banks, 1904) na depreciação quantitativa e qualitativa da produção algodoeira. Biológico, São Paulo, v.40, p. 139-149, 1974.

RAIJ, B.V.; CANTARELLA, H; QUAGGIO, J.A.; FURLANI, A.M.C. (Ed.). Recomendações de adubação e calagem para o Estado de São Paulo. 2 ed. Campinas: Instituto Agronômico \& Fundação IAC, 1997. 285p. (Boletim Técnico, 100). 
SANTOS, W.J. Monitoramento e controle das pragas do algodoeiro. In: CIA, E.; FREIRE, E.C.; SANTOS, W.J.

(Ed.). Cultura do algodoeiro. Piracicaba: POTAFOS, 1999. p.133-179.

SCHUSTER, M.F.; MAXWELL, F.G; JENKINS, J.N.

Antiobiosis to twospottedo spider mite in upland and American pima cotton. Journal of Economic Entomology, v.65, n.4, p. 1110-1111, 1972.
VIEIRA, M.R.; CHIAVEGATO, L.G. Biologia de Polyphagotarsonemus latus (Banks, 1904) (Acari: Tarsonemidae) em algodoeiro. Pesquisa Agropecuária Brasileira, v.33, n.9, p.1437-1442, 1998.

Recebido em 9/8/07

Aceito em 21/11/08 